\title{
Promoting the priorities of practitioner research engagement
}

[This is the manuscript of Hall, H. (2010). Promoting the priorities of practitioner research engagement. Journal of Librarianship and Information Science, 42(2). For the published version, please see issue 2 of volume 42 of Journal of Librarianship and Information Science.]

\section{By Hazel Hall}

Director - Centre for Social Informatics, Edinburgh Napier University

Hazel Hall is Director of the Centre for Social Informatics at Edinburgh Napier University. She is seconded part-time two days a week to the lead the implementation of the Library and Information Science Research Coalition.

\section{Address:}

Centre for Social Informatics

School of Computing

Edinburgh Napier University

10 Colinton Road

Edinburgh EH10 5DT

Edinburgh Napier contacts

Tel +44 (0)131455 2760

E-mail:h.hall@napier.ac.uk

Twitter: @hazelh

Library and Information Science Research Coalition contacts

Tel +44 (0)7 969078181

E-mail:hazel.hall@lisresearch.org

Twitter: @LISResearch 


\section{Abstract}

One of the aims of the Library and Information Science Research Coalition is to promote library and information science practitioner research. Successfully meeting this aim should result in greater use of the existing knowledge base and the creation of new knowledge on LIS practice. LIS practitioner engagement in research should also be channelled to build an evidence base that demonstrates the value and impact of LIS practice. Possible means of the LIS practitioner community meeting these goals is discussed with reference to the support offered by the Library and Information Science Research Coalition.

KEYWORDS: British Library, Chartered Institute of Library and Information Professionals, impact, Joint Information Systems Committee, Library and Information Science Research Coalition, libraries, Museums, Archives and Libraries Council, practitioners, research, Research Information Network, value. 


\section{Introduction}

The Library and Information Science (LIS) Research Coalition was established in 2009 by the British Library, the Chartered Institute of Library and Information

Professionals, the Joint Information Systems Committee, the Museums Libraries and Archives Council, and the Research Information Network with the broad mission of facilitating a coordinated and strategic approach to LIS research across the UK. The initial activities of the implementation have focussed on providing a formal structure to improve access to LIS research in the UK, with the goal of maximising its relevance and impact. The initiatives that the Coalition has supported to date, and which will be developed further in the future, aim to:

1. bring together information about LIS research opportunities;

2. encourage dialogue between research funders;

3. promote LIS practitioner research and the translation of research outcomes into practice;

4. articulate a strategic approach to LIS research;

5. promote the development of research capacity in LIS. 
This article discusses the challenges related to the third of these aims: the promotion of LIS practitioner research and the translation of research outcomes into practice. Of particular interest are efforts to raise awareness of the importance of engagement in research amongst LIS practitioners so that the application of outcomes of earlier studies becomes routine in the workplace, and a greater proportion of practitioners actively undertake research themselves. Through these activities there is the potential for the value of the existing knowledge base of the profession to be increased: it will be more intensively exploited, as well as enlarged by the contributions from practitioner researchers. The discussion that follows is set against the context of current debates around research value and impact, highlighting the need for the development of an evidence base dedicated to demonstrating the value and impact of library and information services.

\section{LIS practitioner engagement with research}

Evidence suggests that managers routinely ignore published studies that would provide a better basis for decision-making than the means more commonly taken 
(Pfeffer \& Sutton, 2006). The Special Libraries Association, in its most recent Research Statement published in 2001, observed how this problem applies to LIS:

As information professionals, it seems logical that we should recognize the need to create, share and use our own knowledge base in information and library science; however, this has not necessarily been the case in the past. Like other professional groups, librarians tend to be action-oriented, relying on our own experience and professional judgment to make decisions.

(Special Libraries Association, 2001)

There are, of course, reasons why practitioners are often obliged to make decisions without referring to the extant literature of the domain, a process that has been labelled 'evaluation bypass' (Booth, 2006, p. 355). For example, the multi-disciplinary nature of the LIS literature, found across publications in numerous domains, militates against straightforward access to appropriate evidence (Booth, 2006, p. 356; Koufogiannakis \& Crumley, 2006, p. 334). From the perspective of the provision of library and information services, however, decision-making that fails to take into account what is known already - whether deliberately or unintentionally - risks substandard services delivery. End-users who rely on the services in question directly 
suffer the negative impacts of this. In addition, and more significantly when the longterm health of a service is taken into consideration, politically important LIS stakeholders - such as those in control of funding - may draw unfavourable conclusions on service value when they base these on evidence of under-performing units.

If few LIS practitioners make systematic use of the research literature, even lower numbers actively engage in the full range of LIS research activities that lead to the wide dissemination of research findings. A quick scan of the contents pages of the LIS research journal literature confirms that academic researchers dominate the formal publication space. Indeed, ambitions for the publication of work in the most prestigious international peer-reviewed journals are generally confined to a particular type of practitioner. For example, on the occasion that Library and Information Science Research receives submissions from LIS practitioners, these are almost always from North American academic librarians in tenured positions, or individuals with ambitions for such roles (C. Schwartz, personal communication, $23^{\text {rd }}$ January 2010). 
It is somewhat ironic that members of a profession that comprises specialists in supporting the research efforts of others have neglected the evidence base of their own subject domain:

... librarians are regarded as experts at searching for evidence to support the practice of other professionals but are very unlikely to do the same for their own practice.

(Booth, 2002. p. 56)

This problem is evident even in the general understanding of job titles in the field. Consider, for example, the term 'Research Librarian' and how it may be understood as a role that centres on assisting others in conducting research, rather than one where the core work is research in the domain of librarianship. In contrast, this ambiguity does not apply to job titles such as 'Research Scientist': here there is no doubt as to whether or not the scientist in question is involved in empirical work.

There are, however, many reasons to account for the low engagement of LIS practitioners in research endeavours. These relate both to the execution of research and its dissemination. The most significant is the resource available to support such 
work. The current funding infrastructure for LIS research in the UK has become less favourable to practitioners in the past two decades as the main source of support for LIS research has passed from one organisation to another, each successively less focussed on LIS than the body from which it inherited its new remit. The journey of funding responsibility is neatly summarised by Feather (2009) in his article on the development of academic research in the LIS domain: from the British Library Research and Development Department, to the Library and Information Commission, to the Museum, Archives and Libraries Council, and ultimately to the Arts and Humanities Research Council. Once in the hands of the Arts and Humanities Research Council, whose wide remit is clear in its nomenclature, Feather explains that 'LIS academics found themselves competing in a new and far harsher climate, and practitioner researchers were effectively excluded from obtaining funding' (2009, p. 179).

The current regime makes it difficult not only for practitioners to source funding for major research projects, but also cuts out the communication channels through which they can influence the forthcoming research agenda. There is perhaps less incentive for practitioners to write research proposals as responsive bids for projects defined by bodies with which they have no regular involvement at the level of 
research strategy development. A more attractive proposition would be to seek funding for empirical studies designed on the basis of their own (more relevant) research ideas. A related resourcing issue is time, where competing service requirements are prioritised over research work. In short, if research is not regarded as a key component of the role of LIS practitioner, then it is difficult to argue for time to be allocated to such activity as part of the working week.

As well as access to resources in terms of funding and time, a further barrier that stands in the way of potential practitioner researchers is their lack of recognition of their own research skills and abilities. Since the 1990s it has been a requirement of accredited UK LIS degree programmes to offer research methods as core to course provision. It may be concluded that there are two decades worth of UK LIS graduates who have (or had) a grounding in research skills that is currently under-exploited.

One way by which less confident practitioner researchers might start to engage in research is to seek partners or mentors. Linking up with experienced academics, for example, may appear attractive. However, working with a partner often demands compromises. In the case of partnership with academic staff, practitioners can find themselves obliged to follow an undesirable joint path as academics work to an 
agenda that offers rewards for the publication of research results, whereas practitioners would rather undertake the translation of results for end user and policy audiences.

A more positive observation is that some practitioners who claim not to be research active actually are. It is conceivable that they do not recognise as research their involvement in short-term projects that require the gathering and collating of data (for example by gathering responses to a question sent out to a listserv), and reporting findings. The issues here then are less to do with how to embark on research, and more concerned with the dissemination of findings.

Too often the results of in-house research projects are trapped within the confines of practitioners' own organisations or, at best, sectors. This is due to a number of reasons. First, practitioners may be unaware of the value and application of their work to a wider audience. As a result, research output is only reported to the immediate local constituency, such as research sponsors, and possibly to the users set to benefit from the findings. It is, of course, understandable for a profession that values close relationships with its client-base to follow this practice. However, it is rare that LIS research outcomes would be so unique that nobody else, such as other 
practitioners and researchers (and possibly funders and those responsible for setting LIS research strategy), would be interested in seeing them:

... researchers must be aware that information research makes an impact not only upon the information profession but also upon the organizations and agencies that employ information professionals and in which decisions on applications are often made by people other than the professional information worker. Their publications, therefore, should be aimed at the appropriate target.

(Craghill \& Wilson, 1987, p. 73).

This especially true for themes that are common concerns across the LIS landscape, for example: means of enhancing community engagement; challenges of serving increasingly diverse user groups; the impact of social media on information services provision; the effect of digitisation projects on scholarly communication; capitalising on the move to mobile devices as the preferred platform for information delivery; predictions for future roles of LIS staff; perceptions of Google as a cost-free library replacement; strategies for marketing library and information services etc. 
In cases where there is recognition that it would be worth disseminating the results of projects, practitioner researchers often lack the knowledge of how to pass their learning on to others through the formal channels. An initial challenge is to identify a suitable outlet. For example, aiming too high with a first submission risks rejection. Alternatively aiming too low may result in acceptance, but here there is a chance that important research findings will not reach the wide audience that they deserve: this is typically the case for unpublished conference papers. Equally practitioner researchers may submit their work in a form that is simply not suitable for publication in the target journal or conference, even though the content is worthy of publication. For example, manuscripts may be refused due to failure to follow precise submission requirements of particular journal titles.

It is clear that practitioners face a number of challenges related to engagement in research, whether as users of the existing knowledge base, or as active researchers intent on designing and conducting empirical studies with a view to communicating their findings to the profession at large. 


\section{Building evidence bases: the need to contribute to the knowledge of the} domain, and to demonstrate LIS value and impact

It is argued above that decision-making is enhanced when reference can be made to a body of domain-specific knowledge. It is therefore important that the LIS profession encourages practitioner research and its dissemination through appropriate channels. Added to these arguments is the view that for a professional practitioner community to be taken seriously, it needs to be seen by outsiders as one whose practice is underpinned by research investment:

A profession... that fails to demand research support within its own budget with the same level with which it clamors for operating support, will ultimately earn the perception that what it does is routine, clerical, and ultimately dispensable.

(Libraries for the future, c1998)

Thus visibly building a domain-specific knowledge-base has a political, as well as practical, function. In short, professions that invest in research activity earn a higher 
status than those that do not. Research investment should be regarded as an essential component of the practitioner role, rather than a luxury.

This argument may be extended with reference to a particular line of research: domain-specific impact studies. In recent months the term 'impact' has been much debated in UK higher education. This is in the context of the proposal that impact should account for $25 \%$ of the assessment of research output in the forthcoming Research Excellence Framework (REF) (the successor to the Research Assessment Exercise (RAE)) (Higher Education Funding Council for England, 2009). While UK academics across all subject domains considered responses to this specific proposal, LIS leaders showed more general concern that the profession cannot currently access an evidence base that demonstrates the positive impact of its practice: to date librarians and information scientists have not measured the worth of their work in precise terms with reference to the broader context in which they operate ${ }^{1}$. For example, in his presidential address on $15^{\text {th }}$ October 2009 Peter Griffiths, President of the Chartered Institute of Library and Information Professionals, acknowledged that academic researchers have a role to play in building such an evidence base, but this type of researcher cannot bring practical experience to the discussion of the

\footnotetext{
${ }^{1}$ This is not to say that the theme of impact is ignored in the research literature. It is acknowledged that a large proportion of LIS research focuses on impact in bibliometric studies.
} 
value of library and information services (Griffiths, 2009). He encouraged the practitioner members of his audience to consider how they could help assemble the evidence base. Griffiths' successor, Biddy Fisher, also declared that the role of practitioners in demonstrating the value and impact of LIS would be on her agenda for 2010 (Hyams, 2010, pp. 34-35).

LIS leaders are conscious that the development of an evidence base of this nature is not without challenges, not least due to the problem of measuring contributions that are largely intangible. How, for example, may improvements in quality of life in a community be demonstrated as a direct effect of public library initiatives, or high student satisfaction ratings in national university league tables be attributed to efforts of academic librarians to enhance the library space for study and learning? Difficult though this may be, it is not impossible. For example, at the Online conference in December 2009 Tenopir outlined a series of studies undertaken by consultants, researchers and librarians working together to test methods of measuring return on investment in libraries (Tenopir, 2009). 
Regardless of the challenges that executing this type of work raises, in economic hard times there is a pressing need to demonstrate worth on the basis of strong arguments that can be substantiated ${ }^{2}$. As Griffiths (2009) declared:

No more fluffy statements about how good libraries are: in the postrecession world... we must PROVE the value we provide with hard evidence.

(Griffiths, 2009, p. 61).

A strong evidence base derives from well-executed research, the results of which are accessible both to professional peers and the wider community of LIS stakeholders. Without a body of active practitioner researchers it is near impossible to assemble the data from which levels of impact can be assessed and publicised. This leaves services vulnerable to cost-cutting exercise. Funders will protect units where contributions to organisational objectives and the bottom line are more clearly articulated, not least as demonstration of accountability for their actions.

\footnotetext{
${ }^{2}$ As demonstrated in a booklet published by Research Councils UK in 2009. This quantified the value of scientific research in short snippets of information, for example 'Research on the bluetongue virus has saved $£ 485$ million through the prevention of outbreaks and has protected 10,000 UK jobs' (Research Councils UK, c2009, p. 2).
} 


\section{Means of promoting LIS practitioner research}

It has been established that there is a need for practitioner research to be promoted more explicitly. This is both for the sake of the generation of new knowledge and its transfer in LIS in general, and - perhaps more urgently - to grow an evidence base that supports continued investment in library and information services.

In recent years strong examples of good practice in promoting LIS practitioner research have emerged in two sectors: medicine and academia. The most prominent LIS practitioner researchers form part of the evidence-based librarianship (EBL) movement, or - in its most recent incarnation - the evidence-based library and information practice (EBLIP) movement. EBLIP is defined as:

an approach to information practice that promotes the collection, interpretation and integration of valid, important and applicable userreported, librarian-observed, and research-derived evidence. The best available evidence, moderated by user needs and preferences, is applied to improve the quality of professional judgements.

(Booth \& Brice, 2004). 
Since it was in the domain of medicine that the concept of evidence-based research was established, the early adopters of this approach are medical librarianship practitioners. Similarly much of the work in the field of EBLIP is UK-based due to the geographical origins of the evidence-based research. A wider appreciation of the methods deployed in EBLIP would help with efforts to add practitioner research findings from the full range of sectors to the knowledge-base of the domain. It is to the UK LIS community's benefit that a number of EBLIP pioneers are based in the UK.

A further example of how practitioner research is encouraged highlights practice in academic libraries. For a number of years North American academic librarians who seek tenured posts as faculty members have been required to show evidence of research activity and publication output. In some cases this has been achieved with employer support (Miller \& Benefiel, 1998, p.261). The academic institutions that have reported most success in practitioner research have provided infrastructural supports such as mentoring, peer support, research clubs and funding, as well as made explicit the expectation that research is part of the job role of an academic librarian (Fennewald, 2008, p. 104). Whilst this approach is not commonplace in the UK, elements of the techniques deployed are evident in some academic librarian job descriptions. For example, the Research Support Specialist role established at the 
University of Northampton in 2007 has the remit of fostering a culture which encourages colleagues to be open to using and undertaking research, and to sharing innovative practices. In addition research-related activity is embedded in the staff development and career review process (M. Pickton, personal communication, $23^{\text {rd }}$ January 2010).

The Library and Information Science Research Coalition has taken a number of steps to promote practitioner research with the intention that these will lead to the translation of research outcomes into practice. The first has been a drive to encourage LIS practitioners to become receptive to the idea of research so that they start to regard it as a component of their job role. By the end of $2009 / 10$ this message will have reached a range of specific LIS practitioner audiences including those working in academia ${ }^{3}$, medicine ${ }^{4}$ and business $^{5}$. It will also have been conveyed at events that attract a mix of LIS practitioners ${ }^{6}$ including the Coalition's

\footnotetext{
${ }^{3}$ Society of College, National and University Libraries Autumn conference, November $17^{\text {th }} 2009$. See http://lisresearch.org/2009/11/18/lis-research-coalition-presentation-at-the-sconul-autumnconference/

${ }^{4}$ Health Information and Libraries for Evaluation and Research (HEALER) meeting, March $18^{\text {th }} 2010$

${ }^{5}$ Business Librarians Association conference, July $7^{\text {th }}-9^{\text {th }} 2010$. See http://www.bbslg.org/2010Conference.aspx

${ }^{6}$ For example, Online 2009, December $1^{\text {st }}-3^{\text {rd }} 2009$ (see http://lisresearch.org/2009/12/09/lisresearch-coalition-\%e2\%80\%9creview\%e2\%80\%9d-of-online-2009/) and CILIP North West AGM, March $3^{\text {rd }} 2010$.
} 
own conference at the British Library Conference Centre on June $28^{\text {th }} 2010$. By raising awareness of the value of engagement in research activity, it is hoped that those who have not previously routinely referred to the research output of others in the course of their work might start to do so, then move to using this output to direct decisions related to services provision. It is conceivable that those already involved in research projects will feel more motivated to disseminate their findings more widely than had previously been the case. Ultimately a community of practitioners with ambitions to publish in the most highly rated international peerreviewed scholarly journals may emerge as a long-term impact of the Coalition's work to foster an interest in LIS practitioner research.

The Coalition recognises that LIS practitioners work in highly pressurised environments and many do not have time to keep up with all the latest research. In response to this, the Coalition works on the development of tools and guides to help researchers access resources to support research work. The Coalition web site serves as an information hub for a number of key resources, such as links to: 
- web sites of UK bodies that fund LIS research http://lisresearch.org/links/

- individual events of specific interest to the LIS research community http://lisresearch.org/events/

- networks associated with LIS research in the UK http://lisresearch.org/links/

- individual LIS research centres in the UK http://lisresearch.org/links

- resources maintained by CILIP's Library and Information Research Group, covering bibliographic databases, research listings, journals, organisational web sites, resource portals, mailing and discussion lists and conference details http://lisresearch.org/links/

- the five main international LIS conference listings services http://lisresearch.org/events//

- output of the 2008 Research Assessment exercise http://lisresearch.org/links//

@LISResearch, the Coalition's Twitter feed, relays research-related information of interest to LIS researchers. This includes coverage of LIS research news such as: funding opportunities; studentships; jobs; invitations to join committees, take part in consultations and contribute to the research projects of others; new publications - 
research reports, monographs, journal issues; training events; calls for papers; prizes; forthcoming conferences etc. By following @LISResearch or subscribing to the RSS feed, LIS researchers have an efficient means of keeping up to date with research news of specific relevance to LIS, and may be encouraged to become more proactive in their research efforts, for example by responding to calls for papers, offering their services on a committee or contributing to someone else's research project by completing an online survey.

These online resources also offer the facility for two-way traffic. @LISResearch followers who have a message to reach a wide community of individuals interested in LIS research issues send material to be tweeted from the @LISResearch account. Similarly, content on the Coalition web pages grows in response to suggestions from the LIS research community at large.

Longer term it is anticipated that the Coalition will support a number additional activities that will interest and engage the LIS research community. These include research methods training workshops. Other possible initiatives may be the provision of summaries on current research topics, or the sponsorship of discussion fora for research evaluation. The Coalition welcomes suggestions from the 
community at large as it strives to promote LIS practitioner research as part of it broad mission to facilitate a coordinated and strategic approach to LIS research in the UK.

\section{Conclusion}

The Library and Information Science Research Coalition has made clear its intention to promote LIS practitioner research in order to address a number of issues. These include the under-use of the extant body of knowledge, and the need to grow an evidence base to support declarations of the value of library and information services. It is hoped that the practitioner community will recognise and share this mission, and partner the Coalition in its efforts to raise awareness of LIS practitioners' responsibilities to engage with research as a means of informing their own work and that of others. The longer term benefits of such activities should strengthen the position of LIS practitioners, both as researchers and in general, and lead to the creation of a larger set of professionals who will be positioned to contribute to future research agendas in LIS. 


\section{Acknowledgements}

The author thanks Candy Schwartz and Miggie Pickton for discussing elements of the content of this article. She also is grateful to the Board of Directors of the Library and Information Science Research Coalition for comments on the manuscript draft. 


\section{References}

Booth, A. (2002). 'Mirage or reality?' Heath Information Libraries Journal, 19: 56-58.

Booth, A. (2006). 'Clear and present questions: formulating questions for evidence based practice', Library Hi Tech, 24 (3): 355-368.

Booth, A. \& Brice, A. (2004). Why evidence-based information practice? In: Booth A., Brice A. (eds). Evidence based practice for information professionals. London: Facet, 1-12.

Craghill, D. \& Wilson, T.D. (1987). The Impact of Information Research. British Library Research Paper 20. London: British Library.

Feather, J. (2009). LIS research in the United Kingdom: Reflections and prospects. Journal of Librarianship and Information Science, 41, 173-181.

Fennewald, J. (2008). 'Research productivity among librarians: factors leading to publications at Penn State', College and Research Libraries 69 (2): 104-116.

Griffiths, P. (2009). 'Shifting the library paradigm', Library and Information Update. November: 56-62.

Higher Education Funding Council for England (2009). Research Excellence Framework: Second Consultation on the Assessment and Funding of Research. Bristol: HEFCE.

Hyams, E. (2010). 'Professionalism: the pride and the passion'. Library and Information Update, January/February: 34-36.

Koufogiannakis, D., \& Crumley, E (2006). 'Research in librarianship: issues to consider', Library Hi Tech 24 (3): 324-340.

Libraries for the future (c1998). Library Research 1983-1997. Washington, DC:

National Institute on Postsecondary Education, Libraries and Lifelong Learning. URL http://www.ed.gov/offices/OERI/PLLI/LibraryResearch/iffnew2.pdf (consulted 23rd January 2010). 
Miller, J.P. \& Benefiel, C.R. (1998). 'Academic librarians and the pursuit of tenure: the support group as a strategy for success', College and Research Libraries, 59 (3): 260265.

Pfeffer, J. \& Sutton, R.I. (2006). 'Evidence-based management', Harvard Business Review, January: 63-74.

Research Councils UK (c2009). Excellence with Impact. UR 4http://framework.rcuk.ac.uk/cmsweb/downloads/rcuk/framework/framework.p df (consulted 23 January 2010).

Special Libraries Association (2001, June). SLA research statement. URL http://www.sla.org/content/resources/research/rsrchstatement.cfm (consulted 24 January 2010)

Tenopir, C. (2009). 'Return on investment in academic research libraries: phase $2-$ the role of libraries in the grants process'. In: C. Turner, C. (ed.), Proceedings of $33^{\text {rd }}$ International Online Meeting, London, December 1-3 2009. London: Incisive Media, 117-122. 